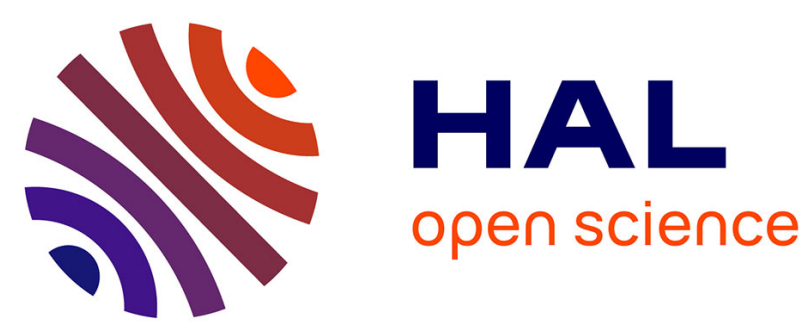

\title{
Is low birth weight in the causal pathway of the association between maternal smoking in pregnancy and higher BMI in the offspring?
}

\author{
Andreas Beyerlein, Simon Rückinger, André Michael Toschke, Angelika \\ Schaffrath Rosario, Rüdiger Kries
}

\section{To cite this version:}

Andreas Beyerlein, Simon Rückinger, André Michael Toschke, Angelika Schaffrath Rosario, Rüdiger Kries. Is low birth weight in the causal pathway of the association between maternal smoking in pregnancy and higher BMI in the offspring?. European Journal of Epidemiology, 2011, 26 (5), pp.413420. 10.1007/s10654-011-9560-y . hal-00675393

\section{HAL Id: hal-00675393 \\ https://hal.science/hal-00675393}

Submitted on 1 Mar 2012

HAL is a multi-disciplinary open access archive for the deposit and dissemination of scientific research documents, whether they are published or not. The documents may come from teaching and research institutions in France or abroad, or from public or private research centers.
L'archive ouverte pluridisciplinaire HAL, est destinée au dépôt et à la diffusion de documents scientifiques de niveau recherche, publiés ou non, émanant des établissements d'enseignement et de recherche français ou étrangers, des laboratoires publics ou privés. 
1 Is low birth weight in the causal pathway of the association between maternal smoking

2 in pregnancy and higher BMI in the offspring?

3 Andreas Beyerlein ${ }^{1}$, Simon Rückinger ${ }^{1}$, André Michael Toschke ${ }^{2}$, Angelika Schaffrath

4 Rosario $^{3}$, Rüdiger von Kries ${ }^{1}$

$5{ }^{1}$ Ludwig-Maximilians University of Munich, Institute of Social Paediatrics and Adolescent

6 Medicine, Division of Epidemiology, Munich, Germany

$7{ }^{2}$ Ludwig-Maximilians University of Munich, Department of Medical Informatics, Biometry

8 and Epidemiology (IBE) and Munich Centre of Health Sciences (MC-Health), Munich,

9 Germany

$10 \quad{ }^{3}$ Robert Koch-Institute, Berlin, Germany

11

12 Corresponding author:

13 Andreas Beyerlein, MSc

14 Ludwig-Maximilians University of Munich

15 Institute for Social Paediatrics \& Adolescent Medicine

16 Heiglhofstrasse 63

1781377 Munich

18 Germany

19 Tel.: +49-89-71009-120

20 Fax: +49-89-71009-315

21 E-mail: andreas.beyerlein@med.uni-muenchen.de

23 Running title: Smoking in pregnancy and childhood overweight

24 Key words: KiGGS, smoking, overweight, obesity, body mass index, birth weight 
Abstract

Introduction: A number of cross-sectional and prospective studies suggested a priming effect of maternal smoking in pregnancy on offspring's obesity. It has been hypothesized that this association might be explained by low birth weight and subsequent catch-up growth in the causal pathway. We therefore examined the role of birth weight in children exposed vs. not exposed to cigarette smoking in utero on later body mass index (BMI).

Methods: Using data of 12,383 children and adolescents (3-17 years of age) recorded in a German population-based survey (KiGGS), we assessed mean body mass index standard deviation scores (BMI-SDS) in different birth weight SDS categories, stratified for children with smoking and non-smoking mothers. We calculated spline regression models with BMISDS as outcome variable, cubic splines of birth weight SDS, and potential confounding factors.

Results: Children whose mothers had been smoking during pregnancy had lower birth weight SDS and higher BMI-SDS at interview compared to children of non-smoking mothers. However, we observed a linear association between birth weight SDS and BMI-SDS in crude analyses for both groups. Similarly, almost linear effects were observed in adjusted spline regression analyses, except for children with very low birth weight. The respective 95\% confidence bands did not preclude a linear effect for the whole birth weight SDS distribution.

Discussion: Our findings suggest that low birth weight is unlikely to be the main cause for the association between intrauterine nicotine exposure and higher BMI in later life. Alternative mechanisms, such as alterations in the noradrenergic system or increased food efficiency, have to be considered. 


\section{Introduction}

50 A number of cross-sectional and prospective studies have suggested a priming effect of maternal smoking in pregnancy on offspring's overweight (1-12). Although the epidemiological evidence for this association is consistent, the underlying mechanisms remain largely unknown.

Low birth weight is another well-established adverse effect of maternal smoking in pregnancy (13-15). Infants with low birth weight are known to catch up their weight and to a smaller extent their height deficit within the first two years of life $(16,17)$. Catch-up growth has also been established and confirmed in meta-analyses as an important risk factor for overweight and the metabolic syndrome later in life (18).

Therefore, it appears possible that low birth weight and subsequent catch-up growth might

60 explain the association between intrauterine nicotine exposure and childhood overweight.

61 However, in most studies birth weight was considered as a linear confounding variable (1, 3,

62 5-7, 9-12) despite an assumed J-shaped relationship between birth weight and later 63 overweight (19).

64 In order to examine the role of birth weight for the association of maternal smoking in 65 pregnancy and offspring's overweight explicitly, we used spline regression methods to assess potential non-linear effects of birth weight on later body composition, analysing data from a large German population-based survey on children and adolescents. 
$70 \quad$ Subjects and data

71 The data were collected from May 2003 to May 2006 in the German Health Interview and 72 Examination Survey for Children and Adolescents (KiGGS), a representative nation-wide survey on children and adolescents selected within 167 communities (primary sample points). In a second step, addresses of families were drawn randomly from local registries to invite the children to participate in the survey. The study was approved by the Institutional Review Board of the Virchow-Klinikum of the Humboldt-University Berlin. A detailed description of the survey has been published elsewhere $(20,21)$. Overall, $n=17,641$ children aged 0 to 17 years were enrolled.

Information on covariates and life style factors was obtained from self-administered questionnaires from parents and also from the children themselves (in children aged 11 years and older). For non-German families with poor command of the German language, questionnaires in their native languages were provided. Maternal smoking in pregnancy was documented in three categories (never, occasionally or regularly) and dichotomised to never or any. Maternal body mass index (BMI) was calculated from self-reported height and weight at interview. Maternal age was recorded in years. Children were classified as having a migration background either if they were immigrated from another country and at least one of their parents was not born in Germany, or if both parents were immigrants or were of nonGerman nationality (22). Socioeconomic status (SES) was classified based on the parents' professional status, income and educational achievements and assigned to low, middle or high according to the parent with the higher status, with about $1 / 4$ of the children and adolescents falling into the lowest category $(23,24)$. Breastfeeding (yes/no) refers to any breastfeeding of the index child as reported by the mothers. The child's TV viewing time per day was recorded separately for working days and weekends in the following categories (ordinal value in brackets): none (1), 0.5 hours (2), 1-2 hours (3), 3-4 hours (4), >4 hours (5). We summed the 
values of working days and weekend TV viewing time up and defined high TV viewing time as a summary score of $\geq 7$. For questions related to their pregnancy, e. g. concerning birth weight or gestational age at birth, parents were encouraged to consult their "maternity pass". In Germany, every pregnant woman receives this booklet for complete documentation of antenatal care visits and is advised to keep it for possible subsequent pregnancies for likewise documentation.

Children's height was measured, without wearing shoes, by trained staff with an accuracy of $0.1 \mathrm{~cm}$, using a portable Harpenden stadiometer (Holtain Ltd., Crymych, UK). Body weight was measured with an accuracy of $0.1 \mathrm{~kg}$, wearing underwear, with a calibrated electronic scale (SECA, Birmingham, UK). These measures were used to calculate children's BMI. To adjust children's BMI for sex and age, we transformed the observed BMI values to sex- and age-specific standard deviation scores (SDS) established by the World Health Organisation (WHO) $(25,26)$ using the LMS method (27).

Likewise, we calculated sex- and gestational age-specific SDS values for birth weight (recorded in grams) based on German reference percentiles $(28,29)$. Preterm birth was defined by gestational age $<37$ weeks if gestational age was reported or if parents reported premature birth otherwise.

We excluded 2,805 children aged 0 to 2 years, since BMI measurements do not allow for an appropriate definition of overweight in this age group. Further 355 children not living with their biological mother were excluded as were 705 children with missing values on BMI-SDS or birth weight and 145 children for whom information about maternal smoking during pregnancy was missing. Since children of smoking mothers are more likely to be born prematurely, and premature birth and the associated illnesses during the first few weeks of life might influence the relationship between birth weight and BMI in childhood, we further excluded preterm children from our analyses. Restriction to term born children (1,248 further exclusions) yielded a final dataset of $n=12,383$ observations. If gestational age at birth was 
121 unknown but term birth was reported $(\mathrm{n}=1,505 ; 12.2 \%)$, a gestational age of 39 weeks was

122 assumed corresponding to the mean gestational age in German term births (30).

\section{$124 \quad$ Statistical analysis}

125 Unadjusted mean values of BMI-SDS were estimated for different birth weight SDS 126 categories (<-2, -1.5 to $-1,-1$ to $-0.5,-0.5$ to 0,0 to $0.5,0.5$ to 1,1 to $1.5,1.5$ to 2 and $>2$ ) and

127 stratified by pregnancy smoking status of their mothers. To examine potentially differential 128 effects by child's age (and by potential differences in maternal recall of smoking habits during 129 pregnancy after time), a further stratification by four age groups (3-6 years, 7-10 years, 11-13 130 years and 14-17 years) was carried out in a supplementary analysis.

131 To adjust for potential confounders, we calculated spline regression models $(31,32)$ on the

132 whole dataset. We considered BMI-SDS as outcome variable, birth weight SDS as continuous explanatory variable, maternal smoking during pregnancy as a binary explanatory variable,

134 and maternal BMI, maternal age at birth of the index child (both continuous), high TV 135 viewing time (as a proxy for low physical activity), migration background, exclusive formula136 feeding and low parental SES (all dichotomous) as potential confounding factors. To assess 137 potential non-linear effects, birth weight SDS was modelled by cubic splines with three 138 degrees of freedom (df), since the respective regression model showed a slightly superior fit 139 to models with one or two df, as determined by the Akaike Information Criterion (33). Again, 140 we stratified for maternal smoking in pregnancy (thus without this variable as predictor in the 141 respective models). This approach allowed us to quantify and visualize potentially different 142 effects in children whose mothers smoked or did not smoke during pregnancy. Additionally, 143 we stratified for offspring's sex in order to address potential sex-specific effect modifications.

144 In a sensitivity analysis, we further adjusted for child's age (modelled by cubic splines with 145 three df). The rationale for these supplementary analyses was to preclude potential age146 specific confounding effects which might arise if the BMI-SDS values derived from external 
147 reference values would not be in accordance with the BMI development in German children.

148 In a further sensitivity analysis, we used regular (instead of any) smoking during pregnancy as

149 explanatory and stratifying variable, respectively.

150 All calculations were carried out with R 2.9.0 (http://cran.r-project.org). All analyses were

151 done with weighted estimates based on weights accounting for the two-staged sample design.

152 We included only observations with full information about all covariates into the regression

153 analyses (complete case analysis). Cluster effects within the sample points were considered

154 negligible and were not incorporated in the analysis.

155 
157 The mean BMI-SDS of the subjects analysed was 0.32, indicating that these children and

158 adolescents had slightly higher BMI values compared to the population on which the WHO z-

159 scores had been calculated. Children whose mothers had been smoking during pregnancy had

160 lower birth weight SDS values, but higher BMI-SDS values at interview compared to children

161 of non-smoking mothers (table 1). Due to the sample design, children's age was rather equally

162 distributed, with a mean age of 10.8 years in the children analysed. Maternal smoking during

163 pregnancy was positively associated with low parental SES, high TV viewing time, exclusive

164 formula-feeding, a lower maternal age at birth of the index child and a slightly increased

165 maternal BMI. Each binary-coded potential risk factor for overweight except migration

166 background had a prevalence of $<25 \%$ in children of non-smoking mothers and of $<50 \%$ in

167 children of smoking mothers.

168 For both groups an unadjusted linear association between birth weight SDS and BMI-SDS

169 was observed (figure 1). However, the mean BMI-SDS values of children whose mothers had

170 smoked during pregnancy were above the upper limits of the 95\% BMI-SDS confidence

171 intervals of non-smoking mothers in any birth weight SDS interval. Similar patterns were

172 observed in all age groups considered (data not shown).

173 In adjusted regression analyses, maternal smoking during pregnancy was associated with a

174 mean increase of 0.31 [95\% CI: 0.25, 0.36] in BMI-SDS independent of effects of the

175 considered confounders, including non-linear effects of birth weight SDS (table 2). Figure 2

176 shows predicted BMI-SDS values by birth weight SDS (conditional for the effects of the

177 confounding factors), indicating an almost monotonous association between these two

178 variables in the adjusted analyses except for a slight inverse effect in birth weight SDS values

179 below -2 . However, the implemented boxplot indicated that the proportion of observations

180 with very low birth weight was small $(<5 \%)$, with predicted BMI-SDS values of $<0$ for this

181 subgroup. The respective 95\% confidence bands did not exclude a linear effect for the whole 
182 birth weight SDS distribution. Similar findings were observed in the subgroups of children of

183 both smoking and non-smoking mothers (figure 2). Further analyses did not yield evidence 184 for effect modification by offspring's sex (supplementary figure).

185 The results of the spline regression models were almost identical if child's age was added as a

186 potential confounder in sensitivity analyses, and if regular smoking was used as explanatory 187 or stratifying variable (data not shown).

188 


\section{Discussion}

190 While confirming the well known association between maternal smoking in pregnancy and

191 body composition in childhood / adolescence, we did not detect evidence for low birth weight

192 being in its causal pathway: Maternal smoking in pregnancy was strongly associated with

193 higher offspring's BMI independent of potential non-linear effects of birth weight in our data.

194 We observed an almost monotonous association between birth weight and later BMI in

195 children of both smoking and non-smoking mothers, excluding a decisive role of low birth

196 weight in determining obesity in children of smoking mothers.

197 Our crude analyses suggest a rather linear association between birth weight and BMI-SDS in

198 children of both smoking and non-smoking mothers. This association may be somewhat

199 stronger in children of smoking mothers, but the confidence limits in the smoking group -

200 especially at higher birth weight values - were too wide to draw final conclusions on that.

201 However, the primary finding from these analyses was that we consistently observed a higher

202 BMI-SDS in children of smoking mothers compared to children of non-smoking mothers,

203 irrespective of their birth weight. If low birth weight was the main cause for obesity in

204 children of smoking mothers, one would rather expect to find higher BMI-SDS values in

205 children with low birth weight, irrespective of the smoking status of their mother (but a higher

206 proportion of children of smoking mothers falling into the low birth weight category).

207 This interpretation is in keeping with our findings from adjusted analyses: Only for children

208 with birth weight SDS values below -2 , an inverse relation between birth weight and later

209 BMI appeared possible from our data. An SDS value of -2 represents the $3^{\text {rd }}$ percentile of the

210 reference distribution, corresponding with birth weights of $2690 \mathrm{~g}$ or less in males and $2570 \mathrm{~g}$

211 or less in females born in the $39^{\text {th }}$ week of gestation (28). It is unlikely, though, that the

212 association between maternal smoking in pregnancy and offspring obesity can mainly be

213 explained by a small effect which affects less than $5 \%$ of a population. Furthermore, the 
respective predicted BMI-SDS values were $<0$, therefore not indicating an increased risk for

215 overweight in this subgroup compared to the mean population.

216 These findings are in accordance with results from a recent study from our study group, which 217 had suggested that overweight in children exposed to tobacco smoking in utero was 218 apparently not mediated through foetal growth retardation (34). However, this study was 219 limited by the fact that it was based on data from 1986-88 with a relatively small sample size $(\mathrm{n}=561)$. We are aware of only one further study examining the type of relationship between birth weight and overweight in childhood in the context of pregnancy smoking. In this study, four categories of birth weight were analysed alongside pregnancy smoking and other factors as potential predictors of overweight at 4.5 years (35). The authors concluded that low birth weight was not in the causal pathway of maternal smoking in pregnancy and offspring's overweight. Interestingly, crude analyses for all children (irrespective of maternal smoking status) showed that, compared to the reference category (3000-4000 g), a lower risk for overweight occurred in the second-lowest (2500-2999 g), but not in the lowest birth weight category $(<2500 \mathrm{~g})$, which is in accordance with our findings.

In addition, other studies on overweight in children and adults showed that the association of 230 maternal smoking in pregnancy and offspring's overweight in adulthood was robust to 231 adjustment for offspring's birth weight $(1,5,6,9)$. Also, results from the Dutch famine study suggested that persons whose mothers had been exposed to famine during their pregnancy were more likely to be overweight in later life, irrespective of their birth weight (36).

234 Other recent studies, however, have suggested a role of (low) birth weight in the pathway of 235 the association of intrauterine nicotine exposure and later overweight $(4,7,8,37)$. Based on our data, a potential role of low birth weight for offspring's later overweight is not confined to children of smoking mothers: Although birth weight was slightly shifted towards lower values

238 in children of smoking mothers, the mostly linear association between birth weight and later BMI was maintained. 
240 A study on Sprague-Dawley rats suggested differential effects of intrauterine nicotine 241 exposure by sex (38). There is, however, only scarce epidemiological evidence for this 242 assumption. While two studies suggested that potential effects might be stronger in male 243 children $(39,40)$, others showed similar odds ratios for overweight and obesity in male and 244 female offspring $(5,41)$. The results from the latter studies are well in accordance with those 245 from our previous study (34) and the present one, in neither of which we found indications of 246 sex-specific effect modifications.

247 Interestingly, our main results remained virtually unchanged when we examined the effects of 248 regular smoking during pregnancy. However, these findings should not be overinterpreted, 249 since the mothers in our study did not get a reference point for what would be considered as 250 "occasional" or "regular" smoking (e. g. in terms of cigarettes per day) when they filled out 251 their questionnaires. It is also possible that regularly smoking mothers might have been 252 inclined to underreport their smoking as occasional, thus blurring the difference between "regular" and "occasional".

254 The validity of most of the variables considered in this study is likely to be high. Children's 255 BMI was calculated from weight and height measured by trained staff. Parents were 256 encouraged to consult their "maternity passes" when answering the questions on gestational age and weight at birth. Recall of smoking habits has been reported to yield valid results in general (42), but the validity of self-reported smoking in pregnancy - which was also the standard method of smoking assessment in other studies (1, 3-15) - is doubtful, since the 260 number of smoking mothers might be underestimated (43). However, we do not feel that this 261 limitation should have caused substantial bias to the main results of our study: If a number of mothers who smoked during pregnancy were misclassified as non-smokers, the effect size of smoking on BMI-SDS might even have been underestimated in the overall analyses. In 264 stratified analyses, a small overestimation of the potential effect of very low birth weight 265 might have occurred in children of non-smoking mothers. However, the findings in smoking 
mothers are unlikely to have been biased, since it appears unrealistic that any non-smoking

267 mother was classified as a smoking mother. It may appear debatable whether our findings 268 (and, consequently, those of most previous epidemiological studies on this topic) may have 269 been biased by mothers who did not smoke during their pregnancy but lived together with a 270 smoking partner, thus exposing the fetus to nicotine in a supposedly unexposed pregnancy. 271 Unfortunately, we were not able to examine this potential limitation, because there was no 272 information available on paternal smoking during pregnancy in our data. However, we 273 showed recently that the effect of maternal smoking during pregnancy could only partially be 274 explained by paternal smoking (44).

275 It may be argued that we examined effects on mean BMI-SDS and generalized them with 276 respect to overweight or obesity. Since the effects of a number of risk factors for obesity 277 appear to be stronger on the upper parts of the BMI distribution as recently shown (45), use of 278 the mean BMI is a conservative approach in assessing the effects of maternal smoking on 279 offspring's overweight.

280 It might further be argued that our findings might at least partly be due to psychosocial 281 characteristics associated with smoking in pregnancy. For example, we observed that 282 maternal smoking during pregnancy was positively associated with all other risk factors for 283 childhood overweight in the data analysed. However, our adjusted regression analyses revealed that the effect of smoking on offspring's body composition was independent of these risk factors, and a recent review concluded that confounding is less likely to be a major issue 286 (4). Furthermore, a comprehensive analysis of risk factors for obesity in the KiGGS study, 287 including physical activity and diet, indicated that smoking during pregnancy is indeed an 288 independent risk factor (2). Biological explanations should therefore also be taken into 289 account.

290 Animal studies helping to disentangle the biological mechanism of intrauterine tobacco 291 exposure and later obesity are based on nicotine exposure (46). Studies in rodents with a 
follow-up for at least 10 postnatal weeks reported emergence of higher body weight exposed

293 to nicotine in utero compared to controls $(38,47,48)$. In two of these studies $(38,47)$, mean

294 birth weights were not different between offspring exposed and not exposed. Although some

295 differences do exist between the pregnancies of rodents and humans, these findings suggest

296 that low birth weight does not appear to be a necessary precursor for higher weights in

297 offspring exposed to nicotine in utero.

298 Growth in late pregnancy is likely to affect mainly birth weight while early pregnancy was 299 supposed to be instrumental in the association of fetal tobacco exposure and later obesity (10).

300 Since offspring with intrauterine tobacco exposure were reported to have deficits in impulse 301 control or control of food consumption, we have previously postulated that the mechanism 302 underlying might purely affect appetite behaviour due to alterations of the cholinergic and 303 catecholaminergic neurotransmitter systems (49) that have been linked to learning deficits or 304 the brain's reward system (50). We therefore had postulated that fetal nicotine exposure may 305 result in persistent deficits in impulse control and possible decreased control of food 306 consumption $(9,11)$.

307 Surprisingly a poor rather than an increased appetite was observed after fetal nicotine 308 exposure in rats and in 42 year old adults in the 1970 British Cohort Study $(51,52)$. Other 309 mechanisms seem to be likely involved such as a higher food efficiency or lower physical 310 activity. Indeed, in rodents disruptions in the mesoaccumbens dopaminergic pathway, a 311 decreased thermogenesis or a decreased sympathetic responsiveness resulting in hypoactivity 312 of the noradrenergic system was observed after fetal nicotine exposure or prenatal nicotinic 313 overload (53-55).

314 A higher food efficiency after intrauterine nicotine exposure might be another possible 315 mechanism since fetal nicotine exposure was associated with increased epididymal, 316 mesenteric and perirenal fat pad weights in rodents at 26 weeks (47), hypertriglyceraemia in 7 
317 weeks old Wistar rats (48), enhanced PPAR- $\gamma$ gene expression (also in vitro) (56) or an 318 increased adipocyte differentiation in Sprague-Dawley (51).

319 In summary, it appears unlikely from our findings that the consistently observed increased 320 risk for low birth weight - via subsequent catch-up growth - is the main cause of the higher 321 overweight prevalence in offspring of mothers smoking during their pregnancy. 


\section{Acknowledgements}

324 This work was supported by the Ludwig-Maximilians University Innovative Research Priority 325 Project Munich Center for Health Sciences (sub-projects 1 \& 2), and by grants from the DFG 326 (Deutsche Forschungsgemeinschaft, grant KR 1926/3-1). AMT received grant support from 327 the German 'Competence Net Obesity,' which is supported by the German Federal Ministry 328 of Education and Research (grant number 01 GI0839). However, the hypothesis development, 329 analysis, interpretation and conclusions contained in this study are those of the author's alone.

\section{Conflict of interest}

333 The authors had no conflicts of interest. 


\section{References}

336 1. Adams AK, Harvey HE, Prince RJ. Association of maternal smoking with overweight 337 at age 3 y in American Indian children. Am J Clin Nutr. 2005 Aug;82(2):393-8.

338 2. Kleiser C, Schaffrath Rosario A, Mensink GB, Prinz-Langenohl R, Kurth BM. 339 Potential determinants of obesity among children and adolescents in Germany: results from 340 the cross-sectional KiGGS Study. BMC Public Health. 2009;9:46.

341 3. Mendez MA, Torrent M, Ferrer C, Ribas-Fito N, Sunyer J. Maternal smoking very 342 early in pregnancy is related to child overweight at age 5-7 y. Am J Clin Nutr. 2008 343 Jun;87(6):1906-13.

344 4. Oken E, Levitan EB, Gillman MW. Maternal smoking during pregnancy and child 345 overweight: systematic review and meta-analysis. Int J Obes (Lond). 2008 Feb;32(2):201-10.

346 5. Power C, Jefferis BJ. Fetal environment and subsequent obesity: a study of maternal 347 smoking. Int J Epidemiol. 2002 Apr;31(2):413-9.

348 6. Reilly JJ, Armstrong J, Dorosty AR, Emmett PM, Ness A, Rogers I, et al. Early life 349 risk factors for obesity in childhood: cohort study. BMJ. 2005 Jun 11;330(7504):1357.

350 7. Sharma AJ, Cogswell ME, Li R. Dose-response associations between maternal 351 smoking during pregnancy and subsequent childhood obesity: effect modification by maternal 352 race/ethnicity in a low-income US cohort. Am J Epidemiol. 2008 Nov 1;168(9):995-1007.

353 8. Suzuki K, Ando D, Sato M, Tanaka T, Kondo N, Yamagata Z. The association 354 between maternal smoking during pregnancy and childhood obesity persists to the age of 9-10 355 years. J Epidemiol. 2009;19(3):136-42.

356 9. Toschke AM, Koletzko B, Slikker W, Jr., Hermann M, von Kries R. Childhood 357 obesity is associated with maternal smoking in pregnancy. Eur J Pediatr. 2002 358 Aug;161(8):445-8.

359 10. Toschke AM, Montgomery SM, Pfeiffer U, von Kries R. Early intrauterine exposure 360 to tobacco-inhaled products and obesity. Am J Epidemiol. 2003 Dec 1;158(11):1068-74. 
11. von Kries R, Toschke AM, Koletzko B, Slikker W, Jr. Maternal smoking during

362 pregnancy and childhood obesity. Am J Epidemiol. 2002 Nov 15;156(10):954-61.

363 12. Wideroe M, Vik T, Jacobsen G, Bakketeig LS. Does maternal smoking during 364 pregnancy cause childhood overweight? Paediatr Perinat Epidemiol. 2003 Apr;17(2):171-9.

365 13. Hammoud AO, Bujold E, Sorokin Y, Schild C, Krapp M, Baumann P. Smoking in 366 pregnancy revisited: findings from a large population-based study. Am J Obstet Gynecol. 3672005 Jun;192(6):1856-62; discussion 62-3.

368 14. Lowe CR. Effect of mothers' smoking habits on birth weight of their children. Br Med J. 1959 Oct 10;2(5153):673-6.

15. McDonald AD, Armstrong BG, Sloan M. Cigarette, alcohol, and coffee consumption and prematurity. Am J Public Health. 1992 Jan;82(1):87-90.

372 16. Farooqi A, Hagglof B, Sedin G, Gothefors L, Serenius F. Growth in 10- to 12-year-old children born at 23 to 25 weeks' gestation in the 1990s: a Swedish national prospective 374 follow-up study. Pediatrics. 2006 Nov;118(5):e1452-65.

17. Hack M, Schluchter M, Cartar L, Rahman M, Cuttler L, Borawski E. Growth of very 376 low birth weight infants to age 20 years. Pediatrics. 2003 Jul;112(1 Pt 1):e30-8.

377 18. Ong KK, Loos RJ. Rapid infancy weight gain and subsequent obesity: systematic 378 reviews and hopeful suggestions. Acta Paediatr. 2006 Aug;95(8):904-8.

379 19. Oken E, Gillman MW. Fetal origins of obesity. Obes Res. 2003 Apr;11(4):496-506.

380 20. Kamtsiuris P, Lange M, Schaffrath Rosario A. [The German Health Interview and 381 Examination Survey for Children and Adolescents (KiGGS): sample design, response and 382 nonresponse analysis]. Bundesgesundheitsblatt Gesundheitsforschung Gesundheitsschutz. 2007 May-Jun;50(5-6):547-56.

21. Kurth BM, Kamtsiuris P, Holling H, Schlaud M, Dolle R, Ellert U, et al. The challenge of comprehensively mapping children's health in a nation-wide health survey: design of the German KiGGS-Study. BMC Public Health. 2008;8:196. 
22. Schenk L, Ellert U, Neuhauser H. [Children and adolescents in Germany with a migration background. Methodical aspects in the German Health Interview and Examination Survey for Children and Adolescents (KiGGS)]. Bundesgesundheitsblatt

390 Gesundheitsforschung Gesundheitsschutz. 2007 May-Jun;50(5-6):590-9.

391 23. Lange M, Kamtsiuris P, Lange C, Schaffrath Rosario A, Stolzenberg H, Lampert T.

392 [Sociodemographic characteristics in the German Health Interview and Examination Survey

393 for Children and Adolescents (KiGGS) - operationalisation and public health significance,

394 taking as an example the assessment of general state of health]. Bundesgesundheitsblatt

395 Gesundheitsforschung Gesundheitsschutz. 2007 May-Jun;50(5-6):578-89.

396 24. Winkler J, Stolzenberg H. [Social class index in the Federal Health Survey]. 397 Gesundheitswesen. 1999 Dec;61 Spec No:S178-83.

398 25. World Health Organisation (WHO). Child growth standards. [cited 201012 Jan]; 399 Available from: http://www.who.int/childgrowth/standards/bmi_for_age/en/index.html.

400 26. World Health Organisation (WHO). Growth reference data for 5-19 years. [cited 401201012 Jan]; Available from: http://www.who.int/growthref/en/.

402 27. Cole TJ, Green PJ. Smoothing reference centile curves: the LMS method and 403 penalized likelihood. Stat Med. 1992 Jul;11(10):1305-19.

404 28. Voigt M, Friese K, Schneider KTM, Jorch G, Hesse V. [Short information about 405 percentile values of body measures of new-born babies]. Geburtshilfe Frauenheilkunde. $406 \quad 2002 ; 62: 274-6$.

407 29. Voigt M, Schneider KT, Jahrig K. [Analysis of a 1992 birth sample in Germany. 1: 408 New percentile values of the body weight of newborn infants]. Geburtshilfe Frauenheilkunde. 4091996 Oct;56(10):550-8.

410 30. Schiessl B, Beyerlein A, Lack N, von Kries R. Temporal trends in pregnancy weight 411 gain and birth weight in Bavaria 2000-2007: slightly decreasing birth weight with increasing 412 weight gain in pregnancy. J Perinat Med. 2009;37(4):374-9. 
413 31. Beyerlein A, Fahrmeir L, Mansmann U, Toschke AM. Alternative regression models 414 to assess increase in childhood BMI. BMC Med Res Methodol. 2008;8:59.

415 32. Rigby R, Stasinopoulos D. Generalized additive models for location, scale and shape. 416 Applied Statistics. 2005;54(3):507-54.

417 33. Akaike H. A new look at the Statistical Model Identification. IEEE Transaction on 418 Automatic Control. 1974;19:716-23.

419 34. Rückinger S, Beyerlein A, Jacobsen G, von Kries R, Vik T. Growth in utero and body 420 mass index at age 5years in children of smoking and non-smoking mothers. Early Hum Dev. 4212010 Dec;86(12):773-7.

422 35. Dubois L, Girard M. Early determinants of overweight at 4.5 years in a population423 based longitudinal study. Int J Obes (Lond). 2006 Apr;30(4):610-7.

424 36. Ravelli AC, van Der Meulen JH, Osmond C, Barker DJ, Bleker OP. Obesity at the age 425 of $50 \mathrm{y}$ in men and women exposed to famine prenatally. Am J Clin Nutr. 1999 426 Nov;70(5):811-6.

427 37. Monasta L, Batty GD, Cattaneo A, Lutje V, Ronfani L, Van Lenthe FJ, et al. Early-life 428 determinants of overweight and obesity: a review of systematic reviews. Obes Rev. 2010 429 Oct;11(10):695-708.

430 38. Chen WJ, Kelly RB. Effect of prenatal or perinatal nicotine exposure on neonatal 431 thyroid status and offspring growth in rats. Life Sci. 2005 Jan 28;76(11):1249-58.

432 39. Koshy P, Mackenzie M, Tappin D, Bauld L. Smoking cessation during pregnancy: the 433 influence of partners, family and friends on quitters and non-quitters. Health Soc Care 434 Community. 2010 Sep;18(5):500-10.

435 40. Suzuki K, Kondo N, Sato M, Tanaka T, Ando D, Yamagata Z. Gender differences in 436 the association between maternal smoking during pregnancy and childhood growth 437 trajectories: multilevel analysis. Int J Obes (Lond). 2010 Oct 5. 
438 41. Chen A, Pennell ML, Klebanoff MA, Rogan WJ, Longnecker MP. Maternal smoking 439 during pregnancy in relation to child overweight: follow-up to age 8 years. Int $\mathbf{J}$ Epidemiol. $4402006 \mathrm{Feb} ; 35(1): 121-30$.

441 42. Patrick DL, Cheadle A, Thompson DC, Diehr P, Koepsell T, Kinne S. The validity of 442 self-reported smoking: a review and meta-analysis. Am J Public Health. 1994 Jul;84(7):108644393.

444 43. Shipton D, Tappin DM, Vadiveloo T, Crossley JA, Aitken DA, Chalmers J. Reliability 445 of self reported smoking status by pregnant women for estimating smoking prevalence: a 446 retrospective, cross sectional study. BMJ. 2009;339:b4347.

447 44. von Kries R, Bolte G, Baghi L, Toschke AM. Parental smoking and childhood 448 obesity--is maternal smoking in pregnancy the critical exposure? Int J Epidemiol. 2008 449 Feb;37(1):210-6.

450 45. Beyerlein A, Toschke AM, von Kries R. Risk factors for childhood overweight: shift 451 of the mean body mass index and shift of the upper percentiles: results from a cross-sectional 452 study. Int J Obes (Lond). 2010 Apr;34(4):642-8.

453 46. Somm E, Schwitzgebel VM, Vauthay DM, Aubert ML, Huppi PS. Prenatal nicotine 454 exposure and the programming of metabolic and cardiovascular disorders. Mol Cell 455 Endocrinol. 2009 May 25;304(1-2):69-77.

456 47. Gao YJ, Holloway AC, Zeng ZH, Lim GE, Petrik JJ, Foster WG, et al. Prenatal 457 exposure to nicotine causes postnatal obesity and altered perivascular adipose tissue function. 458 Obes Res. 2005 Apr;13(4):687-92.

459 48. Holloway AC, Lim GE, Petrik JJ, Foster WG, Morrison KM, Gerstein HC. Fetal and 460 neonatal exposure to nicotine in Wistar rats results in increased beta cell apoptosis at birth and 461 postnatal endocrine and metabolic changes associated with type 2 diabetes. Diabetologia. $462 \quad 2005$ Dec;48(12):2661-6. 
49. Levin ED, Wilkerson A, Jones JP, Christopher NC, Briggs SJ. Prenatal nicotine

464 effects on memory in rats: pharmacological and behavioral challenges. Brain Res Dev Brain 465 Res. 1996 Dec 23;97(2):207-15.

466 50. Levin E, Slotkin T. Developmental neurotoxicity of nicotine. . Handbook of 467 developmental neurotoxicology. San Diego, CA: Academic Press; 1998. p. 587-615.

468 51. Somm E, Schwitzgebel VM, Vauthay DM, Camm EJ, Chen CY, Giacobino JP, et al. 469 Prenatal nicotine exposure alters early pancreatic islet and adipose tissue development with 470 consequences on the control of body weight and glucose metabolism later in life. 471 Endocrinology. 2008 Dec;149(12):6289-99.

472 52. Toschke AM, Ehlin AG, von Kries R, Ekbom A, Montgomery SM. Maternal smoking 473 during pregnancy and appetite control in offspring. J Perinat Med. 2003;31(3):251-6.

474 53. Levin ED. Fetal nicotinic overload, blunted sympathetic responsivity, and obesity. 475 Birth Defects Res A Clin Mol Teratol. 2005 Jul;73(7):481-4.

476 54. Navarro HA, Mills E, Seidler FJ, Baker FE, Lappi SE, Tayyeb MI, et al. Prenatal 477 nicotine exposure impairs beta-adrenergic function: persistent chronotropic subsensitivity 478 despite recovery from deficits in receptor binding. Brain Res Bull. 1990 Aug;25(2):233-7.

479 55. Oliff HS, Gallardo KA. The effect of nicotine on developing brain catecholamine 480 systems. Front Biosci. 1999 Dec 1;4:D883-97.

56. Amoruso A, Bardelli C, Gunella G, Fresu LG, Ferrero V, Brunelleschi S. Quantification of PPAR-gamma protein in monocyte/macrophages from healthy smokers and non-smokers: a possible direct effect of nicotine. Life Sci. 2007 Aug 23;81(11):906-15.

Figure 1. Point estimates and 95\% confidence limits of mean BMI-SDS by categories of birth weight SDS $(<-2,-2$ to $-1.5, \ldots)$, stratified for children with mothers smoking or not smoking 488 in pregnancy (age: $3-17$ years). 


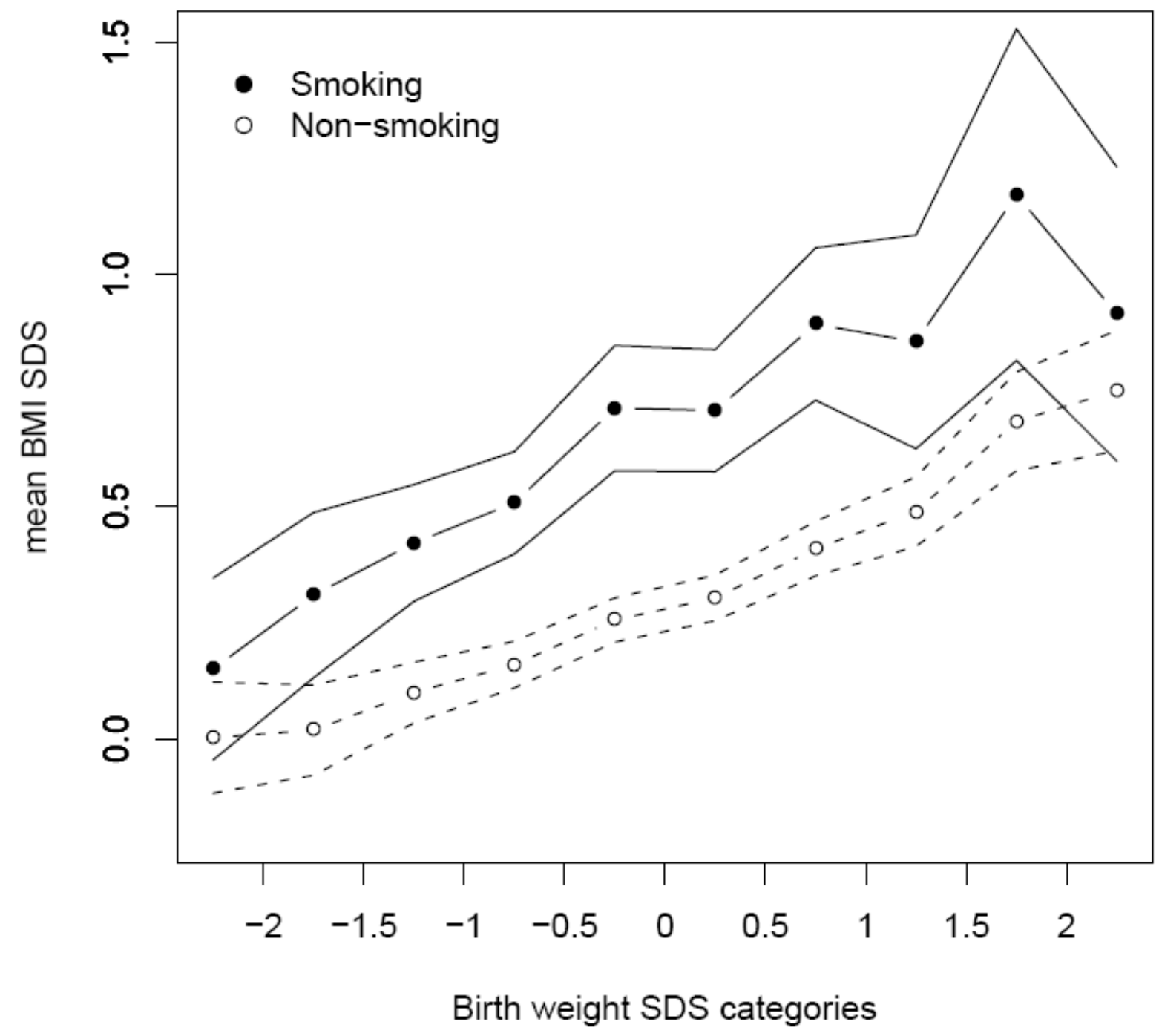

491 Figure 2. Conditional predicted values of BMI-SDS (at 3-17 years) plotted against birth 492 weight SDS in regression models of all children, children of mothers who did not smoke and 493 who smoked during pregnancy, respectively. Models were adjusted for high TV viewing time, 494 breastfeeding, low parental socioeconomic status, migration background, maternal BMI, 495 maternal age at birth of the index child and maternal smoking in pregnancy (if appropriate). 496 The dark grey lines represent pointwise 95\% confidence bands. Boxplots of birth weight SDS 497 are depicted at the bottom of each plot (box $=25^{\text {th }}$ to $75^{\text {th }}$ percentile, whiskers $=5^{\text {th }}$ to $95^{\text {th }}$ 498 percentile, points $=$ outliers $)$. 
All children

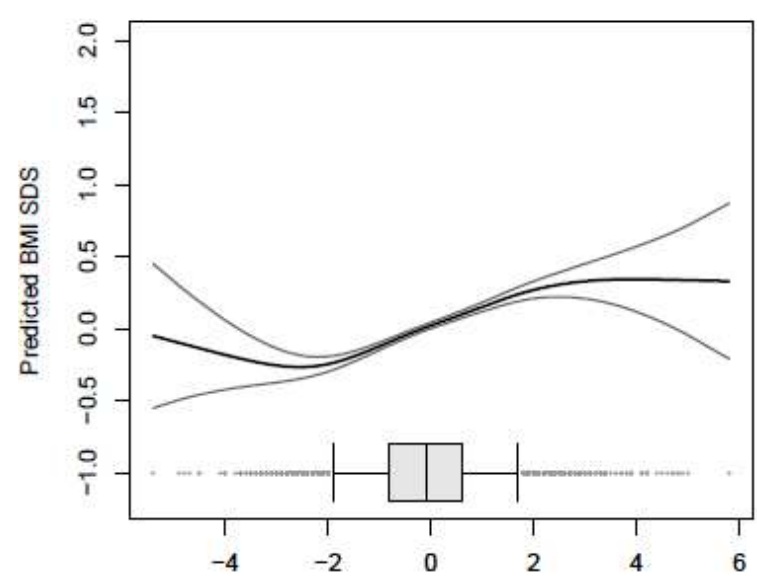

Birth weight SDS

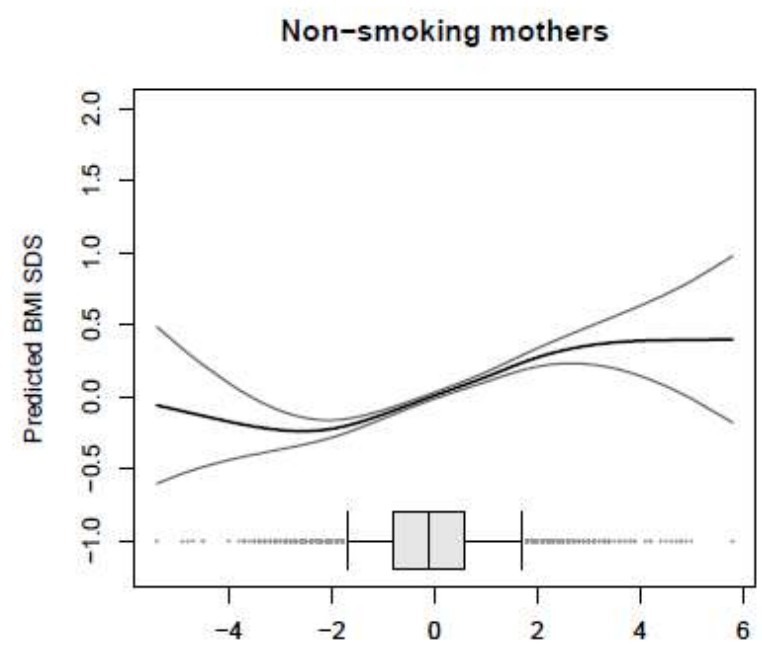

Birth weight SDS

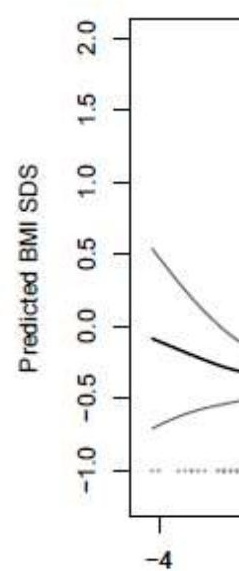

Table 1. Study characteristics of the data analyzed $(n=12,383)$. Two-sided p-values for comparison of non-smoking and smoking mothers (during pregnancy) are based on twosample t-tests or Fisher's exact test as appropriate.

\begin{tabular}{|l|l|l|l|}
\hline & Non-smoking & Smoking mothers & p-value \\
& mothers & $(\mathbf{n}=\mathbf{2 , 0 4 8})$ & \\
\hline & Mean (SD) & Mean (SD) & \\
\hline Birth weight [g] & $3,467(472)$ & $3,318(500)$ & $<0.01$ \\
\hline Birth weight SDS & $-0.07(1.08)$ & $-0.41(1.16)$ & $<0.01$ \\
\hline Child's BMI at interview $\left[\mathrm{kg} / \mathrm{m}^{2}\right]$ & $18.7(3.8)$ & $19.5(4.5)$ & $<0.01$ \\
\hline Child's BMI-SDS & $0.28(1.11)$ & $0.59(1.22)$ & $<0.01$ \\
\hline Maternal BMI $\left[\mathrm{kg} / \mathrm{m}^{2}{ }^{*}\right.$ & $24.5(4.7)$ & $24.8(4.8)$ & $<0.05$ \\
\hline Maternal age at birth of the index & $28.6(4.8)$ & $27.2(5.3)$ & $<0.01$ \\
\hline child [years]* & & & \\
\hline
\end{tabular}




\begin{tabular}{|l|l|l|l|}
\hline & $\mathbf{n}(\mathbf{\%})$ & $\mathbf{n}(\boldsymbol{\%})$ & \\
\hline Male children & $5,251(50.8 \%)$ & $1,016(49.6 \%)$ & 0.33 \\
\hline Low parental social status* & $2,231(21.6 \%)$ & $953(46.5 \%)$ & $<0.01$ \\
\hline Exclusive formula-feeding* & $1,731(16.7 \%)$ & $765(37.4 \%)$ & $<0.01$ \\
\hline High TV viewing time* & $2,429(23.5 \%)$ & $772(37.7 \%)$ & $<0.01$ \\
\hline Migration background* & $1,791(16.5 \%)$ & $253(17.1 \%)$ & 0.58 \\
\hline Child's age y-6 years & $2,724(26.4 \%)$ & $580(28.3 \%)$ & --- \\
\hline 11-10 years & $2,944(28.5 \%)$ & $607(29.6 \%)$ & --- \\
\hline & $2,148(20.8 \%)$ & $415(20.3 \%)$ & - \\
\hline
\end{tabular}
$\mathrm{n}=47(0.4 \%)$, parental social status: $\mathrm{n}=43(0.3 \%)$, formula-feeding: $\mathrm{n}=82(0.7 \%)$, TV viewing time: $\mathrm{n}=308(2.5 \%)$, migration background: $\mathrm{n}=34(0.3 \%)$

Table 2. Regression coefficients [95\% confidence intervals] of predictors for child's BMI-

512 SDS (age: 3-17 years, $\mathrm{n}=11,788$ ).

\begin{tabular}{|l|l|}
\hline Predictor variable & Effect estimate \\
\hline Maternal smoking in pregnancy & $0.31[0.25,0.36]$ \\
\hline Birth weight SDS (per additional unit) & $0.12[0.11,0.14]^{*}$ \\
\hline High TV viewing time & $0.15[0.11,0.20]$ \\
\hline Exclusive formula-feeding & $0.02[-0.03,0.07]$ \\
\hline Low parental social status & $0.09[0.04,0.14]$ \\
\hline Migration background & $0.09[0.03,0.15]$ \\
\hline Maternal BMI (per additional $\mathrm{kg} / \mathrm{m}^{2}$ ) & $0.06[0.05,0.06]$ \\
\hline Maternal age at birth of the index child (per year) & $0.00[0.00,0.00]^{* *}$ \\
\hline
\end{tabular}


$513 *$ modelled using cubic splines

$514 * * * \mathrm{p}>0.05$

515

516 